\title{
Fen Bilimleri Öğretmen Adaylarının Fen-Teknoloji-Mühendislik-Matematik (FeTeMM)'e Yönelik Özyeterlik Ölçeği: Türkçe’ye Uyarlama, Geçerlik ve Güvenirlik Çalışması
}

\author{
Burcu Gelen ${ }^{1}$, Behiye Akçay $^{2}$, Aydın Tiryaki $^{1}$, İbrahim Benek ${ }^{1}$
}

${ }^{1}$ Lisansüstü Eğitim Enstitüsü, İstanbul Üniversitesi-Cerrahpaşa, İstanbul, Türkiye

${ }^{2}$ Matematik ve Fen Bilimleri Eğitimi Bölümü, Hasan Ali Yücel Eğitim Fakültesi, İstanbul Üniversitesi-Cerrahpaşa, İstanbul, Türkiye

Sorumlu Yazar: Behiye Akçay, bbezir@gmail.com

Makale Türü: Araştırma Makalesi

Kaynak Gösterimi: Gelen, B., Akçay, B., Tiryaki, A., \& Benek, İ. (2019). Fen bilimleri öğretmen adaylarının Fen-TeknolojiMühendislik-Matematik (FeTeMM)'e Yönelik Özyeterlik Ölçeği: Türkçe’ye uyarlama, geçerlik ve güvenirlik çalışması. Eğitimde Kuram ve Uygulama, 15(1), 88-107. doi: 10.17244/eku.395204

\section{Pre-Service Science Teachers' Self-Efficacy toward Science, Technology, Engineering, Mathematics} (STEM) Survey: An Adaptation to Turkish, Validity and Reliability Study

\author{
Burcu Gelen $^{1}$, Behiye Akçay ${ }^{2}$, Aydın Tiryaki $^{1}$, İbrahim Benek $^{1}$ \\ ${ }^{1}$ Institute of Graduate Education, Istanbul University-Cerrahpasa, İstanbul, Turkey \\ ${ }^{2}$ Department of Mathematics and Science Education, Hasan Ali Yücel Faculty of Education, Istanbul University-Cerrahpasa, \\ Istanbul, Turkey
}

Corresponding Author: Behiye Akçay, bbezir@gmail.com

Article Type: Research Article

To Cite This Article: Gelen, B., Akçay, B., Tiryaki, A., \& Benek, İ. (2019). Fen bilimleri öğretmen adaylarının Fen-TeknolojiMühendislik-Matematik (FeTeMM)'e Yönelik Özyeterlik Ölçeği: Türkçe’ye uyarlama, geçerlik ve güvenirlik çalışması. Eğitimde Kuram ve Uygulama, 15(1), 88-107. doi: 10.17244/eku.395204 


\title{
Fen Bilimleri Öğretmen Adaylarının Fen-Teknoloji-Mühendislik-Matematik (FeTeMM)'e Yönelik Özyeterlik Ölçeği: Türkçe’ye Uyarlama, Geçerlik ve Güvenirlik Çalışması
}

\author{
Burcu Gelen ${ }^{1}$, Behiye Akçay ${ }^{2}$, Aydın Tiryaki ${ }^{1}$, İbrahim Benek ${ }^{1}$ \\ ${ }^{1}$ Lisansüstü Eğitim Enstitüsü, İstanbul Üniversitesi-Cerrahpaşa, İstanbul, Türkiye \\ ORCID: http://orcid.org/0000-0001-8630-087X \\ ORCID: http://orcid.org/0000-0001-5888-1689 \\ ORCID: http://orcid.org/0000-0002-7124-4905 \\ ${ }^{2}$ Matematik ve Fen Bilimleri Ĕ̆itimi Bölümü, Hasan Ali Yücel Ĕ̆itim Fakültesi, İstanbul Üniversitesi-Cerrahpaşa, İstanbul, \\ Türkiye \\ ORCID: http://orcid.org/0000-0002-0546-8759
}

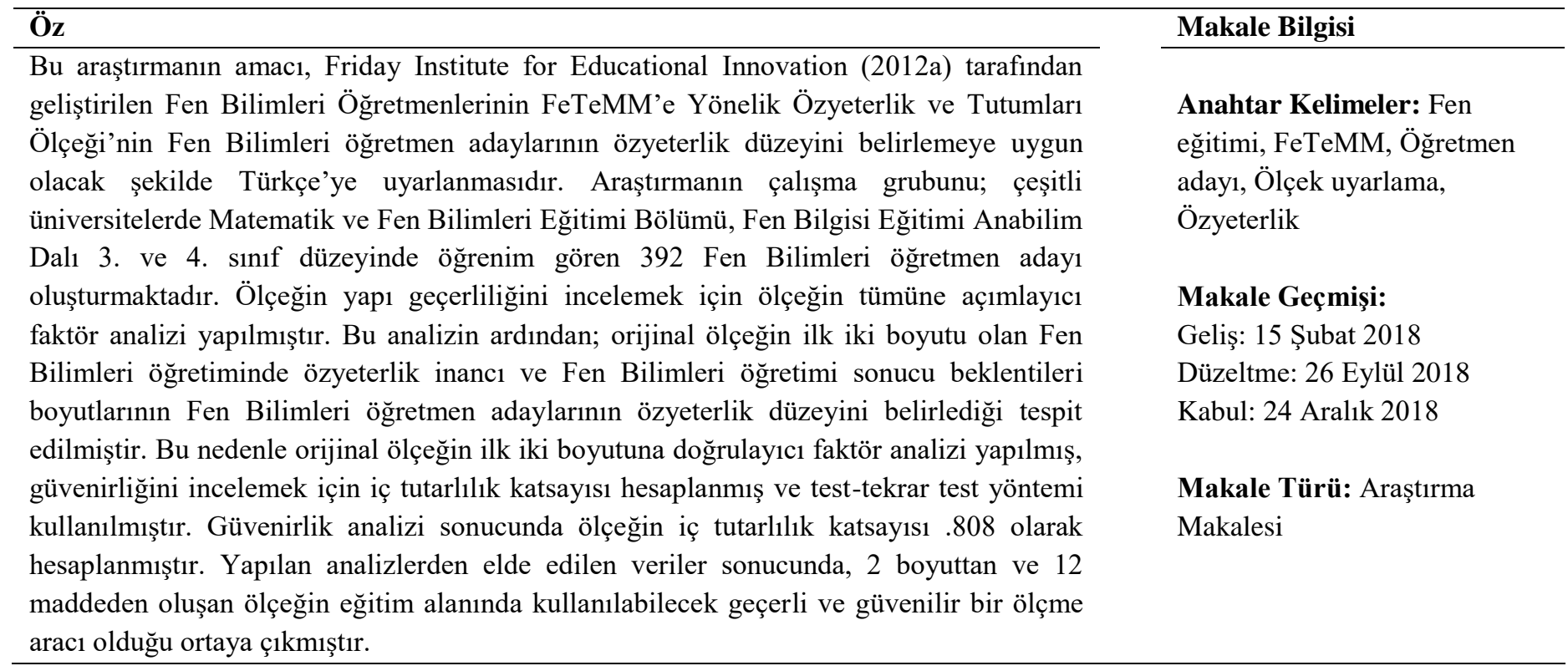




\section{Pre-Service Science Teachers' Self-Efficacy toward Science, Technology, Engineering, Mathematics (STEM) Survey: An Adaptation to Turkish, Validity and Reliability Study}

\begin{abstract}
The aim of this research is to adapt Teacher Efficacy and Attitudes Toward STEM Survey-Science Teachers Scale developed by the Friday Institute for Educational Innovation (2012a) to Turkish. This scale was adapted to Turkish to be determine the selfefficacy level of pre-service Science teachers. The study group of this research was constituted by 392 pre-service Science teachers who are studying at the 3rd and 4th grade levels of Department of Mathematics and Science Education, Science Education Program. In order to examine the construct validity of the scale, exploratory factor analysis was performed to whole scale. Following this analysis; it was found that Science Teaching Efficacy factor and Beliefs and Science Teaching Outcome Expectancy factor, the first two factors of the original scale, were determined the self-efficacy levels of pre-service Science teachers. Therefore; confirmatory factor analysis was performed to the first two factors of the original scale, the internal consistency coefficient was calculated and the test-retest method was used to assess the reliability of scale. As a result of the reliability analysis, the internal consistency coefficient was found as .808. According to data obtained from analysis, it has been revealed that the scale consisting of 2 factors and 12 items is a valid and reliable instrument which can be used in the field of education.
\end{abstract}




\section{Giriş}

Küreselleşen bilgi çağ 1 olarak görülen 21. yüzyıl içinde, teknolojide şimdiye kadar görülmemiş düzeyde büyük ve hızlı bir ilerleme gerçekleşmektedir. Küreselleşmeye ve gelişen teknolojiye gösterilen bu eğilim, farklı ve gelişmiş beceriler kazanmış birey ihtiyacını doğurmuştur (Wagner, 2014). 21. yüzyıl becerileri; bireylerin içinde bulunduğu bilgi çağında yaratıcılıklarını, iletişim, birlikte çalışma, eleştirel düşünme ve problem çözme yetenekleri ile bilgi, medya ve teknolojiyle ilgili becerilerini geliştirmeye vurgu yapmaktadır (Patel \& Yelland, 2006).

Değişen toplumsal talepler, eğitim ortamlarında kapsamlı yeniliklere gidilmesini gerektirmektedir (Larson \& Miller, 2011). Böylelikle, sürekli gelişme içinde olan topluma ayak uydurabilen bireylerin 21. yüzyıl becerilerini kazanmalarını sağlayan iddialı ve titiz bir eğitimden geçmeleri gerekliliği öne sürülmüştür (Blair, 2012; Trilling, Fadel \& Partnership for 21st Century Skills, 2009). Bu becerileri kazandıran eğitimin temeli ise; Amerika'da 2001 y1lında Fen eğitimine kazandırılan Science, Technology, Engineering and Mathematics (STEM) uygulamalarına (Zollman, 2012); ülkemizde ise Fen, Teknoloji, Mühendislik ve Matematik (FeTeMM) olarak adlandırılan disiplinler aras1 uygulamalara dayanmaktadır (Çorlu, Adıgüzel, Ayar, Çorlu \& Özel, 2012).

Eğitimde FeTeMM disiplinlerinin birbirinden izole edilmiş şekilde yer alması, bu disiplinlerin verimli şekilde öğrenilememesine neden olmaktadır (Sanders, 2013). Bu durum, 21. yüzyıl becerilerinin öğrencilere kazandırılamamasına yol açmaktadır (Roberts, 2012). Bu olumsuzluğu ortadan kaldırmak için, FeTeMM disiplinleri ile ilgili işgücü ihtiyacını karşılamayı amaçlayan FeTeMM eğitimi ortaya çıkmıştır (National Science Board, 2015). FeTeMM eğitimi, kaliteli eğitim görmüş işgücü aracıllğıyla ekonomik refah düzeyini yükseltmeyi ön plana almaktadır (McDonald, 2016).

Öğrencilerin Fen, Teknoloji, Mühendislik ve Matematik alanlarındaki akademik kavramlar arasındaki bağlantıları günlük yaşamla ilişkilendirerek öğrenmelerini sağlayan FeTeMM eğitimi, disiplinler arası bir yaklaşımdır. $\mathrm{Bu}$ titiz yaklaşım sayesinde öğrenciler FeTeMM okuryazarı olma özelliğini taşımaktadır. FeTeMM okuryazarlığı, karmaşık ve üst düzey problemleri çözmek için Fen, Teknoloji, Mühendislik ve Matematik kavramlarını kullanma becerisidir (Balka, 2011). FeTeMM okuryazarı olan öğrenciler, FeTeMM alanlarının belirgin özelliklerini bilmekte, bu özelliklerin günlük yaşamı nasıl şekillendirdiklerini anlamakta ve FeTeMM ile ilgili konularda yaşanan zorlukları çözmek için farkındalık kazanmaktadır (Bybee, 2013).

Tek bir dinamik çalışma alanını ifade eden FeTeMM eğitimi, birleştirilmiş ve disiplinler arası bir yaklaşımla öğrenciler için uygun öğrenme ortamlarını sağlamaktadır (Carnevale, Smith \&Melton, 2011). FeTeMM eğitimi, dört disiplin arasındaki geleneksel sınırları kaldırarak öğrencilerin bu disiplinler arasındaki bağlantıyı oluşturmalarını sağlayıcı tutarlı bir öğrenme paradigması oluşturmaktadır. Böylelikle, öğrencilerin dünyayı bütünsel olarak algılamalarını teşvik edici, geleceğin liderleri olmalarını sağlayıcı imkanlar sunmaktadır (Asunda, 2011).

FeTeMM, içerdiği alanları bütünleştirerek bireysel ve toplumsal sorunları çözmeyi amaçlamaktadır. Bu çözüm süreci içinde, bireylerin tek bir alanda çok derin bilgilere sahip olmasını, bu bilgileri diğer alanlarda yer alan ve sorunu çözmek için gerekli olan bilgilerle birleştirmesini sağlamaktadır. FeTeMM eğitimi içinde, karmaşık problemleri nasıl çözeceğini öğreten yüksek kaliteye sahip öğrenme ortamlarına vurgu yapıldığı görülmektedir. Böylelikle derin bilgi birikimine sahip ve hangi bilgiyi nerede ve hangi aşamada kullanacağına yönelik seçim yapma becerisine sahip bireyler yetiştirilmektedir (Krajcik \& Delen, 2017).

FeTeMM eğitimi, mühendislik veya teknolojik bağlam içinde öğrencilerin bilimsel veya matematikle ilgili düşüncelerini ortaya çıkarmaları ve bu düşüncelerini kullanmaları için imkan sağlamaktadır (National Research Council, 2014). Bu imkanı sağlamak için öğrencilerin bir tasarım süreci içine dahil edilmesi gerekmektedir. Tasarım, FeTeMM eğitimi içinde öğrencilerin farklı disiplinler hakkındaki düşüncelerini birleştirmek ve günlük yaşamla ilişki kurmalarını gerçekleştirmek için kullanılmaktadır (Sithole vd., 2017). Bu eğitim sayesinde; öğrencilerin okul, toplum ve küreselleşen dünya arasında bağlantı kurmaları sağlanmaktadır. Böylelikle gelecekte karşılaşacakları yeniliklere ayak uydurabilecek, yeni ekonomide rekabet edebilecek güçlü bireyler yetiştirilmektedir (Tsupros, Kohler \& Hallinen, 2009).

FeTeMM eğitimi, öğrencilerin FeTeMM alanlarına bakış açılarında olumlu değişiklikler yapmayı amaçlamaktadır. Öğrencilerin küçük yaşlardan itibaren FeTeMM alanlara yönelik doğru bilgiler edinmeleri, gelecekteki meslek seçimlerine yön vermektedir (Wyss, Heulskamp \& Siebert, 2012). Bu durum, öğrencilerin ileriki yaşlarında FeTeMM alanlarına yönelik kariyer planlamaları yapmalarını sağlamaktadır (Christensen \& Knezek, 2017). 
Öğrencileri FeTeMM ile ilgili mesleklere yönlendirebilmek için öncelikle bu disiplinlere yönelik olumlu tutum geliştirmelerini sağlamak gerekmektedir (Valenti, Masnick, Cox \& Osman, 2016).

FeTeMM eğitiminin gerektirdiği disiplinler arası öğrenme ortamı, günlük hayatla ilişkili problemlere dayalı öğrenme stratejilerini kullanan öğretmenler aracılı̆̆ verdikleri bilgiler yoluyla öğrencilerin akıl yürütmelerini sağlaması, yaratıcılıklarını arttırması ve öğrencileri motive edebilmesi büyük önem taşımaktadır (Rissanen, 2014). Dolayısıyla, öğrencilerin FeTeMM disiplinleri hakkında daha iyi bilgi sahibi olması için nitelikli bireylerden FeTeMM eğitimi almaları gerekmektedir (Avery \& Reeve, 2013).

Öğretmenlerin öğretme yeteneklerine yönelik inançları, bir başka deyişle özyeterlikleri, öğretmenlerin sundukları öğrenme ortamlarını doğrudan etkilemektedir (Sharma, Loreman \& Forlin, 2011). Özyeterlik, belirli kazanımları üretmek için gerekli olan eylem akışını organize etme ve yürütme yeteneklerine olan inançtır (Bandura, 1977). Özyeterlik, öğretmenlerin sınıflarındeki öğrencilerin öğrenme ihtiyaçlarını karşılamaya yönelik inançlarını temsil etmektedir (Hunter, 2016).

FeTeMM eğitimi, öğretmenlerin güçlü ve profesyonel öğrenme imkanı sağladıkları zaman daha etkili olmakta ve öğrenci başarısında artış görülmektedir (Fulton \&Britton, 2011). Böylelikle, neden-sonuç ilişkisi içinde kendi sorgulama süreçlerini yürüten öğrenciler yetiştirilmektedir. Bu imkanı sağlamak için geleceğin öğretmenleri olacak olan öğretmen adaylarının FeTeMM'e yönelik olumlu tutum sergilemeleri ve özyeterliklerinin yüksek olması gerekmektedir (Fulton, Doerr \& Britton, 2010). Bu durum, kaliteli FeTeMM öğretmenleri yetiştirmenin başlangiç noktasının öğretmen adayları olduğunu vurgulamaktadır (Rogers, Winship \& Sun, 2015).

Öğretmenlerin FeTeMM'e uyumlu eğitim ortamı sağlamalarına büyük önem verilmektedir. Bununla birlikte, öğretmen adaylarının FeTeMM'e yönelik doğru bilgilere ve olumlu tutuma sahip olmasına eşit derecede önem verilmesi durumunda 21. yüzyıla ayak uydurabilecek daha fazla bireyin gelişimine destek olunmaktadır (Radloff \& Guzey, 2016). Öğretmen adaylarının FeTeMM'e yönelik özyeterlik düzeyi, gelecekteki öğretmenlik performanslarına yönelik çok güvenilir bir öngörü olma özelliği taşımaktadır (Thompson \& Kanasa, 2016).

Ulusal ve uluslararası düzeyde FeTeMM ile ilgili çalışmaların sayısında her geçen gün artış yaşanmaktadır. $\mathrm{Bu}$ artış, FeTeMM ile ilgili ölçek gereksinimini ortaya çıkarmıştır. Öğretmen adaylarının bilgi, beceri ve sınıf içi uygulamalarını içeren FeTeMM öğretimi hakkında önemli sonuçları ortaya koyan geçerli ve güvenilir ölçek sayısında ciddi bir eksiklik bulunmaktadır (Katzenmeyer \& Lawrenz, 2006). Bununla birlikte, FeTeMM meslekleri hakkında değerlendirme yapmayı sağlayan ölçek sayısında da eksiklik bulunmaktadır (Tyler-Wood, Knezek \& Christensen, 2010).

Geleceğim öğretmenleri olacak olan öğretmen adaylarının FeTeMM'e yönelik izlenimleri, öğretmenlik mesleklerini nasıl yürütecekleri hakkında çıkarım yapılmasına olanak sağlamaktadır. Öğretmen adaylarının FeTeMM'e yönelik olumlu izlenimlere sahip olması, gelecekte FeTeMM'e yönelik olumlu bakış açısı sergileyen ve bu alanlara yönelen öğrenciler yetiştirilebileceğini öngörmektedir. Böylelikle, öğretmen adaylarının FeTeMM'e yönelik nasıl bir izlenime sahip olduğunun ortaya çıkarılması, geleceği nasıl şekillendireceklerini gözler önüne serecektir.

Ulusal düzeyde bakıldığında, ülkemizde Bilgisayar Öğretimi ve Teknolojileri, ilköğretim Matematik ve Fen Bilimleri eğitimi bölümlerinde öğrenim gören öğretmen adaylarına yönelik FeTeMM Farkındalık Ölçeği’ni geliştirme çalışması (Buyruk \& Korkmaz, 2016), Sınıf eğitimi bölümünde öğrenim gören öğretmen adaylarına yönelik Entegre FeTeMM Öğretimi Yönelim Ölçeği'ni uyarlama çalışması (Hacıömeroğlu \& Bulut, 2016), ilköğretim Matematik ve Fen Bilimleri eğitimi bölümlerinde öğrenim gören öğretmen adaylarına yönelik STEM Semantik Farklılık Ölçeği’ni uyarlama çalışması (Kızılay, 2017) ile Fen Bilimleri ve Matematik bölümlerinde öğrenim gören öğretmen adaylarına yönelik STEM Tutum Ölçeği'ni geliştirme çalışması (Derin, Aydın \& Kırkıç, 2017) yapılmıştır. Alanyazın incelendiğinde, Fen Bilimleri öğretmen adaylarının FeTeMM'e yönelik özyeterlik düzeyini inceleyen bir ölçek bulunmadığ1 görülmüştür. Son yıllarda Fen Bilimleri eğitimi içinde FeTeMM alanlarına büyük önem verilmeye başlanmıştır. Dolayısıyla, Fen Bilimleri öğretmen adaylarının meslek hayatlarına başlamadan önce FeTeMM'e yönelik özyeterlik düzeylerinin ulusal düzeyde incelenmesi zorunluğu ortaya çıkmaktadır. Bu nedenle bu araştırmanın amac1, Friday Institute for Educational Innovation (2012a) tarafından geliştirilen Fen Bilimleri Öğretmenlerinin 
FeTeMM'e Yönelik Özyeterlik ve Tutumları Ölçeği’ni Fen Bilimleri öğretmen adaylarının özyeterlik düzeyini ölçecek şekilde Türkçe’ye uyarlamaktır.

\section{Çalışma Grubu}

\section{Yöntem}

$\mathrm{Bu}$ araştırmanın çalışma grubunu çeşitli üniversitelerde (İstanbul Üniversitesi, Kafkas Üniversitesi, Marmara Üniversitesi, Yıldız Teknik Üniversitesi, Yüzüncü Y1l Üniversitesi) Matematik ve Fen Bilimleri Eğitimi Bölümü, Fen Bilgisi Eğitimi Anabilim Dal1 3. ve 4. sinıf düzeyinde öğrenim gören 392 Fen Bilimleri öğretmen adayı oluşturmaktadır. Örneklem büyüklügünün belirlenmesinde, alanyazında genel kabul gören ölçekteki madde sayısının en az 5 katı olması gerektiği kuralı dikkate alınmıştır (Büyüköztürk, Kılıç Çakmak, Akgün, Karadeniz \& Demirel, 2011; Child, 2006; MacCallum, Widaman, Zhang \& Hong, 1999; Tavşanc1l, 2014).

\section{Veri Toplama Aracı}

$\mathrm{Bu}$ araştırma kapsamında Friday Institute for Educational Innovation (2012a) tarafindan geliştirilen Fen Bilimleri Öğretmenleri için "FeTeMM'e Yönelik Özyeterlik ve Tutumları Ölçeği”" (Teacher Efficacy and Attitudes Toward STEM Survey-Science Teachers), Fen Bilimleri öğretmen adayları için özyeterlik düzeylerini belirleyecek şekilde uyarlanmıştır. Ölçeğin orijinal formu; Fen Bilimleri öğretiminde özyeterlik inancı, Fen Bilimleri öğretimi sonucu beklentileri, öğrencinin teknoloji kullanımı, Fen Bilimleri uygulamaları, 21. yüzyıl öğrenme tutumları, öğretmen liderlik tutumları ve FeTeMM meslek farkındalığı olmak üzere yedi boyuttan oluşmaktadır (Tablo 1). Bu boyutların iç tutarlılık güvenirlik katsayıs1 .814 ve .948 arasında sıralanmıştır (Friday Institute for Educational Innovation, 2012b). Bu boyutlar içinde öğrencinin teknoloji kullanımı boyutu; 'Hiçbir zaman', 'Nadiren', 'Yarı zamanlı', 'Genellikle', 'Her zaman' ve 'Uygulanamaz' olmak üzere 6'lı likert tipi derecelendirmeye sahiptir. Fen bilimleri uygulamaları boyutu; 'Hiçbir zaman', 'Nadiren', 'Yarı zamanlı', 'Genellikle' ve 'Her zaman' olmak üzere 5'li likert tipi derecelendirmeye sahiptir. Diğer boyutlar ise; 'Kesinlikle katılmıyorum', 'Katılmıyorum', 'Kararsızım', 'Katılıyorum' ve 'Kesinlikle katılıyorum' olmak üzere 5'li likert tipi derecelendirmeye sahiptir.

Tablo 1: Orijinal ölçeğin psikometrik özellikleri

\begin{tabular}{lll}
\hline Alt Boyutlar & Madde Sayısı & Cronbach Alpha \\
\hline $\begin{array}{l}\text { Fen Bilimleri Öğretiminde Özyeterlik İnancı } \\
\text { (Science Teaching Efficacy and Beliefs) }\end{array}$ & 11 & .908 \\
$\begin{array}{l}\text { Fen Bilimleri Öğretimi Sonucu Beklentileri } \\
\text { (Science Teaching Outcome Expectancy) }\end{array}$ & 9 & .814 \\
$\begin{array}{l}\text { Öğrencinin Teknoloji Kullanımı } \\
\text { (Student Technology Use) }\end{array}$ & 8 & .900 \\
$\begin{array}{l}\text { Fen Bilimleri Uygulamaları } \\
\text { (Science Instruction) }\end{array}$ & 14 & .934 \\
$\begin{array}{l}21 . \text { Yüzyıl Öğrenme Tutumları } \\
\left(21^{\text {st } C e n t u r y ~ L e a r n i n g ~ A t t i t u d e s) ~}\right.\end{array}$ & 11 & .948 \\
$\begin{array}{l}\text { Öğretmen Liderlik Tutumları } \\
\text { (Teacher Leadership Attitudes) }\end{array}$ & 6 & .870 \\
$\begin{array}{l}\text { FeTeMM Meslek Farkındalı̆̆ } \\
\text { (STEM Career Awareness) }\end{array}$ & 4 & .945 \\
\hline Toplam & 63 & \\
\hline
\end{tabular}

\section{İşlem}

FeTeMM ölçeğinin Türkçe'ye uyarlama çalışmasında; (1) uyarlama çalışmasına hazırlık, (2) ölçeğin orijinal dilden Türkçe ye çevrilmesi, (3) ölçeğin Türkçe'den orijinal dile geri çevrilmesi (3) uzman grup tarafından çeviriler arası tutarlı̆̆ın incelenmesi (4) dilsel eş değerlik uygulaması (5) pilot çalışmanın yapılması (6) pilot uygulamanın ardından istatistiksel analizlerin yapılması aşamaları izlenmiştir. 
Uyarlama çalışmasına hazırlık aşamasında öncelikle alanyazın taranarak öğretmen adaylarına yönelik FeTeMM alanında yapılmış mevcut ölçekler incelenmiştir. Bu inceleme sonucunda, Fen Bilimleri öğretmen adaylarına yönelik özyeterlik düzeylerini ölçen bir ölçeğin bulunmadığı görülmüştür. Bu eksik göz önünde bulundurularak uyarlanacak ölçeğe karar verilmiştir. Orijinal ölçeği geliştiren Friday Institute for Educational Innovation'a e-mail aracılığıyla iletişime geçilerek ölçeğin uyarlanmasına ilişkin gerekli izin alınmıştır.

Orijinal ölçeğin maddeleri ve yönergesi beş uzman tarafından Türkçe'ye çevirilmiştir. Orijinal formu Türkçe'ye çeviren uzman grubundan farklı beş uzman tarafından ise İngilizce'ye geri çeviri işlemi gerçekleştirilmiştir. Orijinal dilden Türkçe'ye ve Türkçe'den orijinal dile geri çevirisi yapılan metinler iki dile de hakim Fen Bilimleri eğitimi alanında uzman grup tarafından değerlendirilerek metinler arası tutarlılık incelenmiştir. Bu inceleme içinde dilsel değerlendirmeye ek olarak kavramsal değerlendirmeler yapılarak ölçeğin kapsam geçerliği incelenmiştir. Kapsam geçerliği, ölçme aracının ölçmeyi amaçladığı konuları temsil etme derecesidir (Tavşancıl, 2014). Ölçeğin kapsam geçerliğini incelemenin yollarından birisi uzman grup incelemesidir. Bu inceleme içinde ölçeğin ölçmek istediği niteliği ölçüp ölçmediğiyle ilgili değerlendirmeler alınmaktadır (Şeker \& Gençdoğan, 2014). Bu çalışmada kapsam geçerliği için uzman grup tarafindan aşağıda yer değişiklikler yapılmıştır.

- Öğretmenlere yönelik oluşturulan ölçek maddelerinin öğretmen adaylarına uygunluğu incelenmiştir. Ölçek maddelerinin öğretmen adaylarının anlayabileceği ve cevaplayabileceği düzeyde olduğuna karar verilmiştir.

- 'Öğrencinin teknoloji kullanımı' boyutunun 6'lı likert tipi derecelendirmeye sahip olması değerlendirilmiştir. Eğitimde en çok 5'li likert tipi derecelendirme kullanılmaktadır (Tavşancıl, 2014). Bu nedenle 'uygulanamaz' seçeneğinin çıkartılıp ölçeğin Türkçe formunda yer alan tüm alt boyutların 5'li likert tipi derecelendirmeye sahip olması sağlanmıştır.

- Ölçeğin orijinal formundaki tek olumsuz madde olan ve 'Fen Bilimleri öğretiminde özyeterlik inancı' boyutunda yer alan 5. maddenin (I wonder if I have the necessary skills to teach science) Türkçe'ye olumlu anlam ifade edecek şekilde çevrilmesine (Fen bilimlerini öğretmek için gerekli yeteneklerimin olup olmadığını merak ederim) karar verilmiştir.

- Tüm incelemeler sonucunda gerekli değişiklikler yapılarak Türkçe formun son hali oluşturulmuştur.

Ölçeğin dilsel eş değerliğini incelemek amaciyla orijinal ve Türkçe form, İstanbul Üniversitesi, Eğitim Fakültesi İngiliz Dili Eğitimi Anabilim Dalı üçüncü sınıfta öğrenim gören 46 öğretmen adayına arka arkaya uygulanmıştır. Bu aşamada Şeker ve Gençdoğan'ın (2014) önerdiği şekilde, önce orijinal dildeki test sonra Türkçe'ye çevrilmiş olan test arka arkaya uygulanmıştır. İki formdan elde edilen maddeler düzeyinde Pearson momentler çarpımı korelasyon katsayıları ve ilişkili grup t testi sonuçları hesaplanmıştır.

Ölçeğin pilot çalışması çeşitli üniversitelerde eğitim gören 392 Fen Bilimleri öğretmen adayına uygulanmıştır. Pilot çalışmanın ardından ölçeğin Türkçe formunun geçerlik ve güvenirlik analizleri yapılmıştır. Ölçeğin dilsel eş değerliğii, Açımlayıcı Faktör Analizi (AFA), madde ayırt ediciliği ve güvenirlik analizleri için SPSS 22.0, Doğrulayıcı Faktör Analizi (DFA) için LISREL 9.30 paket programı kullanılmıştır.

Ölçeğin Türkçe formunun geçerliliğini tespit etmek için yap1 geçerliği incelenmiştir. Ölçeğin yapı geçerliğini incelemek için Doğrulayıcı Faktör Analizi (DFA) ve Açımlayıcı Faktör Analizi (AFA) uygulanmıştır. DFA, maddelerin önceden tanımlanmış bir yapıya uygun olup olmadığını test etmede kullanılmaktadır. AFA, bir dizi maddenin hangi yapıları tanımladığını saptamada kullanılmaktadır (Karaca, Yıldırım, Ankaralı, \& Açıkgöz, 2015). Bu çalışmada AFA yoluyla, ölçeğin orijinalinde yer alan 7 boyutun Türkçe formundaki varlığı incelenmiştir. DFA yoluyla ise, çalışmanın amacına uygun olarak özyeterlik düzeyini incelediği belirlenen ilk iki faktörün yapısının Türk öğrenciler üzerinde doğrulanma durumu incelenmiştir.

FeTeMM özyeterlik ölçeğinin Türkçe formunun güvenirliğini tespit etmek için iç tutarlılık katsayısı hesaplanmış ve test-tekrar test yöntemi kullanılmıştır. Test-tekrar test yöntemi, Pearson momentler çarpım korelasyon katsayısına bakılarak ölçeğin belirli bir zaman aralığındaki kararlılığını ve güvenirliğini tespit etmek için kullanılmaktadır (Tavşancıl, 2014). Test-tekrar test güvenirlik çalışması kapsamında ölçeğin Türkçe formu; İstanbul Üniversitesi, Eğitim Fakültesi Fen Bilgisi Eğitimi Anabilim Dalı’nda öğrenim gören 41 öğrenciye üç hafta arayla uygulanmıştır. Alanyazında iki ölçüm arası sürenin 10-20 gün arası (Karaca ve diğerleri, 2015) ve 2-3 veya 4-6 hafta arası (Tavşancı1, 2014) olması önerilmiştir. Uygulamanın ardından öğretmen adaylarının her iki uygulamadan aldıkları 
puanlar arasındaki kararlılık hesaplanmıştır. Ölçeğin madde ayırt ediciliği incelemek için madde-toplam korelasyonu ve \%27’lik alt-üst grup karşılaştırmaları hesaplanmıştır.

\section{Bulgular}

FeTeMM ölçeğinin Türkçe formundan elde edilen verilerin normal dağılıma sahip olup olmadığı incelenmiştir. Örneklem sayısının 50 ve üzeri olması durumunda Kolmogrov-Smirnov testinin kullanılması önerilmektedir (Seçer, 2015). Yapılan Kolmogorov-Smirnov testinin sonucunda p değeri (sig.) anlamsız olarak hesaplanmıştır $(\mathrm{p}=.052>.050)$. Bu inceleme sonucunda, çalışma kapsamında elde edilen verilerin normal dăğlım gösterdiği bulunmuştur (Tablo 2).

Tablo 2: Normallik testi sonuçları

\begin{tabular}{lllllll}
\hline & \multicolumn{2}{c}{ Kolmogorov-Smirnov $^{\text {a }}$} & \multicolumn{3}{c}{ Shapiro-Wilk } \\
& Statistic & Df & Sig. & Statistic & Df & Sig. \\
\hline Toplam & 045 & 392 &, 052 &, 992 & 392 &, 045 \\
\hline
\end{tabular}

a. Lilliefors Significance Correction

\section{Dilsel Eş Değerlik}

FeTeMM ölçeğinin Türkçe formunun dilsel eş değerliğini belirlemek amaciyla test-tekrar test yöntemi kullanılmıştır. İstanbul Üniversitesi, Eğitim Fakültesi İngiliz Dili Eğitimi Anabilim Dalı üçüncü sınıfta öğrenim gören 46 öğretmen adayına arka arkaya uygulanan orijinal ve Türkçe formdan elde edilen maddeler düzeyinde Pearson momentler çarpımı korelasyon katsayıları ve ilişkili grup t testi sonuçları Tablo 3'te gösterilmektedir.

Tablo 3: Dilsel Eş değerlik incelemesi için ilişkili grup t testi sonuçları

\begin{tabular}{llll}
\hline & & Orijinal Form & Türkçe Form \\
\hline Orijinal Form & Pearson Correlation & 1 &, $957^{* *}$ \\
& Sig. (2-tailed) & &, 000 \\
& $\mathrm{~N}$ & 46 & 46 \\
Türkçe Form & Pearson Correlation &, $957^{* *}$ & 1 \\
& Sig. (2-tailed) &, 000 & \\
& $\mathrm{~N}$ & 46 & 46
\end{tabular}

Tablo 3'e göre ölçeğin orijinal formu ile Türkçe formu arasındaki ilişki düzeyinin yüksek olduğu ( $\mathrm{r}=.98$, $\mathrm{p}<.01)$ görülmektedir. Bu sonuçlara göre, Fen Bilimleri öğretmen adayları için uyarlaması yapılan STEM ölçeğinin orijinal formu ile Türkçe formunun dilsel olarak eşdeğer olduğu ve çevirisi yapılan ölçeğin dil geçerliğinin sağlandığı söylenebilir (Seçer, 2015).

\section{Geçerlik}

FeTeMM ölçeğinin Türkçe formunun yapı geçerliği incelenmiştir. Bu inceleme kapsamında faktör analizi yapılmıştır. Bu incelemenin öncesinde, verilerin faktör analizine uygun olup olmadığını incelemek amacıyla KaiserMeyer Olᄀkin (KMO) katsayısı hesaplanmış ve Bartlett Sphericity Testi uygulanmıştır. KMO katsayısı .897 olarak hesaplanmıştır. Ça $\neg$ lş̧ma içerisinde yapılan analiz sonucunda Bartlett Sphericity testi anlamlı bulunmuştur (x2=12538,273; p=0.00). Faktör analizinin yapılabilmesi için KMO katsayısının .05'ten büyük değer alması (Kaiser, 1974) ve Bartlett Sphericity testinin anlamlı çıkması (Büyüköztürk, 2014) gerekmektedir. Bu sonuçlar, FeTeMM ölçeğinin Türkçe formunun faktör analizine uygun olduğunu göstermektedir.

FeTeMM ölçeğinin orijinalinde yer alan 7 boyutun Türkçe formundaki varlığını incelemek amacıyla AFA uygulanmıştır. Ölçekte yer alan maddelerin faktör yükleri arasındaki farkın .1'den az olmaması gerekmemektedir (Büyüköztürk, 2014). Faktörlerin her birinin ölçekte yer alan toplan varyansın en az \%5'ini açıklaması beklenmektedir (Seçer, 2015). Bu nedenlerden dolayı; yapılan AFA sonucunda sonucunda faktör yükleri arasındaki farkın .1'den az olduğu hesaplanan 7., 10., 13., 15., 21., 22., 23., 39., 40., 41., 43, ve 53. madde ile ölçekte yer alan toplam varyansın 
en az \%5'ini açıklamadığı belirlenen faktörlerde yer alan 5., 20., 24., 25., 26., 27. ve 28. madde ölçekten çıkarılmıştır. AFA sonucunda hesaplanan döndürülmüş bileşenler matriksi (rotated component matrix) Tablo 4'te verilmiştir. Tablo 4 incelendiğinde; 1., 3., 30., 37. ve 54. maddenin birden fazla faktör altında toplandığı görülmüştür. Ancak bu maddelerin faktör yükleri arasındaki farkın .1'den fazla olması nedeniyle ölçekten çıkarılmamıştır. Bununla birlikte, 6 boyutun birlikte açıkladığı toplam varyans değeri \%53,364 olarak hesaplanmıştır (Tablo 5).

Tablo 4: Döndürülmüş bileşenler matriksi

\begin{tabular}{|c|c|c|c|c|c|c|c|c|}
\hline \multicolumn{9}{|c|}{ Rotated Component Matrix } \\
\hline & & & & & Component & & & \\
\hline & 1 & 2 & 3 & 4 & 5 & 6 & 7 & 8 \\
\hline s31 & ,790 & & & & & & & \\
\hline s32 & ,773 & & & & & & & \\
\hline s35 & ,724 & & & & & & & \\
\hline s36 & ,721 & & & & & & & \\
\hline s38 & 689 & & & & & & & \\
\hline s33 & 657 & & & & & & & \\
\hline s34 & ,656 & & & & & & & \\
\hline s29 & 641 & & & & & & & \\
\hline s30 & 636 & & & & & & & ,339 \\
\hline s37 & ,595 & & & & & & ,334 & \\
\hline s42 & ,571 & & & & & & & \\
\hline s47 & & 746 & & & & & & \\
\hline s46 & & ,735 & & & & & & \\
\hline s48 & & ,730 & & & & & & \\
\hline s52 & & ,724 & & & & & & \\
\hline s51 & & ,706 & & & & & & \\
\hline s50 & & 703 & & & & & & \\
\hline s49 & & ,702 & & & & & & \\
\hline s45 & & 663 & & & & & & \\
\hline s44 & & ,655 & & & & & & \\
\hline s4 & & & ,753 & & & & & \\
\hline s8 & & & ,750 & & & & & \\
\hline s9 & & & ,711 & & & & & \\
\hline s2 & & & 677 & & & & & \\
\hline s6 & & & 677 & & & & & \\
\hline s11 & & & ,660 & & & & & \\
\hline s3 & & & 626 & & & & ,414 & \\
\hline s1 & & & ,570 & & & & & ,412 \\
\hline s57 & & & & ,786 & & & & \\
\hline s58 & & & & 781 & & & & \\
\hline s56 & & & & ,772 & & & & \\
\hline s59 & & & & ,738 & & & & \\
\hline s55 & & & & ,630 & & & & \\
\hline s54 & & & & 608 & & & & ,342 \\
\hline s63 & & & & & 904 & & & \\
\hline s62 & & & & & 901 & & & \\
\hline s61 & & & & & 891 & & & \\
\hline s60 & & & & & ,766 & & & \\
\hline s18 & & & & & & ,749 & & \\
\hline s12 & & & & & & ,710 & & \\
\hline s17 & & & & & & ,703 & & \\
\hline s19 & & & & & & 671 & & \\
\hline s16 & & & & & & 670 & & \\
\hline s14 & & & & & & 663 & & \\
\hline $\begin{array}{l}\text { Extr } \\
\text { Rota }\end{array}$ & $\begin{array}{l}\text { Metho } \\
\text { ethod }\end{array}$ & $\begin{array}{l}\text { ipal } \\
\text { x wit }\end{array}$ & $\begin{array}{l}\text { ent An } \\
\text { r Norn }\end{array}$ & ion. & & & & \\
\hline
\end{tabular}


Tablo 5: AFA sonucunda hesaplanan varyans değerleri

\begin{tabular}{cccc}
\hline \multirow{0}{*}{} & Total & $\begin{array}{c}\text { Rotation Sums of Squared Loadings } \\
\text { \% of Variance }\end{array}$ & Cumulative \% \\
: & & & \\
\hline \multirow{0}{*}{} & 5,831 & 12,407 & 12,407 \\
2 & 5,184 & 11,031 & 23,438 \\
3 & 4,184 & 8,902 & 32,340 \\
4 & 3,537 & 7,525 & 39,864 \\
5 & 3,274 & 6,966 & 46,830 \\
6 & 3,071 & 6,534 & 53,364 \\
\hline
\end{tabular}

FeTeMM ölçeğinin uyarlanan ve orijinal formunda yer alan maddelerin boyutlara göre dağılımı incelenmiştir. $\mathrm{Bu}$ inceleme sonucunda, orijinal ölçek kapsamında öğrencinin teknoloji kullanımı boyutu içinde yer alan tüm maddelerin uyarlanan ölçekten çıkarıldığ 1 tespit edilmiştir. Bununla birlikte, uyarlanan ölçekte yer alan maddelerin orijinal ölçekte yer alan maddelere benzer şekilde faktörlere dağılım gösterdiği görülmüştür (Tablo 6).

Tablo 6: Uyarlanan ve orijinal ölçekte yer alan maddelerin boyutlara göre dağılımı

\begin{tabular}{|c|c|c|}
\hline & Orijinal Ölçek & Uyarlanan Ölçek \\
\hline $\begin{array}{l}\text { Fen Bilimleri Öğretiminde Özyeterlik } \\
\text { İnancı }\end{array}$ & $\begin{array}{l}\text { 1., 2., 3., 4., 5., 6., 7., 8., 9., } \\
\text { 10., 11. }\end{array}$ & 1., 2., 3., 4., 6., 8., 9., 11. \\
\hline $\begin{array}{l}\text { Fen Bilimleri Öğretimi Sonucu } \\
\text { Beklentileri }\end{array}$ & $\begin{array}{l}\text { 12., 13., 14., 15., 16., 17., 18., } \\
\text { 19., } 20 .\end{array}$ & 12., 14., 16., 17., 18., 19. \\
\hline Öğrencinin Teknoloji Kullanımı & $\begin{array}{l}\text { 21., 22., 23., 24., 25., 26., 27., } \\
28 .\end{array}$ & - \\
\hline Fen Bilimleri Uygulamaları & $\begin{array}{l}\text { 29., 30., 31., 32., 33., 34., 35., } \\
\text { 36., 37., 38., 39., 40., 41., } 42 .\end{array}$ & $\begin{array}{l}\text { 29., 30., 31. 32., 33., 34., 35., } \\
\text { 36., 37., 38., 42. }\end{array}$ \\
\hline 21. Yüzyıl Öğrenme Tutumları & $\begin{array}{l}\text { 43., 44., 45., 46., 47., 48., 49., } \\
\text { 50., 51., 52., 53. }\end{array}$ & $\begin{array}{l}\text { 44., 45., 46., 47., 48., 49., 50., } \\
\text { 51., 52. }\end{array}$ \\
\hline Öğretmen Liderlik Tutumları & 54., 55., 56., 57., 58., 59. & 54., 55., 56., 57., 58., 59. \\
\hline FeTeMM Meslek Farkındalığı & $60 ., 61 ., 62 ., 63$. & $60 ., 61 ., 62 ., 63$. \\
\hline
\end{tabular}

FeTeMM ölçeğinin orijinal formunun ilk iki faktör yapısının çalışmanın amacıyla örtüşecek şekilde özyeterlik düzeyini belirleyen maddelere sahip olduğu belirlenmiştir. $\mathrm{Bu}$ nedenle, ilk iki faktör yapısının toplanan verilerle doğrulanma durumunu incelemek amacıyla DFA uygulanmıştır. Bu incelemede; ki-kare değerinin serbestlik derecesine oranı ( $\chi 2 / \mathrm{sd})$, yaklaşık hataların ortalama karekökü (RMSEA), karşılaştırmalı uyum indeksi (CFI), normlaştırılmış uyum indeksi (NFI), normlandırılmamış uyum indeksleri (NNFI) dikkate alınmıştır. Yapılan DFA sonucunda elde edilen uyum indeksi sonuçları Tablo 4'te verilmiştir. Bu değerlerin kabul edilebilir sınırlar içinde olduğu (Seçer, 2015) tespit edilmiştir.

Tablo 7: Uyum indeksi sonuçları

\begin{tabular}{lll}
\hline Uyum indeksi & Sonuç & Yorum (Seçer, 2015) \\
\hline NFI & $0.896(.90)$ & Kabul edilebilir (=.90 ve üzeri) \\
NNFI & 0.903 & Kabul edilebilir (=.90 ve üzeri) \\
IFI & 0.923 & Kabul edilebilir (=.90 ve üzeri) \\
RFI & $0.871(.90)$ & Kabul edilebilir (=.90 ve üzeri) \\
CFI & 0.922 & Kabul edilebilir $(=.95$ ve üzeri) \\
GFI & 0.910 & Mükemmel uyum (=.90 ve üzeri) \\
AGFI & 0.868 & Kabul edilebilir $(=.80$ ve üzeri) \\
RMR & 0.0732 & Kabul edilebilir $(=.050$ ve $=.080$ arasi $)$ \\
RMSEA & 0.0881 & Kabul edilebilir $(=.050$ ve $=.080$ arasi $)$ \\
$X^{2} /$ sd & 3.6209 & Uygun $(<4)$ \\
\hline
\end{tabular}


DFA sonucunda elde edilen path diyagramı Şekil 1'de verilmiştir. Path diyagramında yer alan her bir maddenin faktör yük değerinin en az .30 olması gerekmektedir (Seçer, 2015). Bu diyagrama göre, bu ölçekte yer alan maddelerin faktör yüklerinin .62 ile .84 arasında değiştiği tespit edilmiştir.

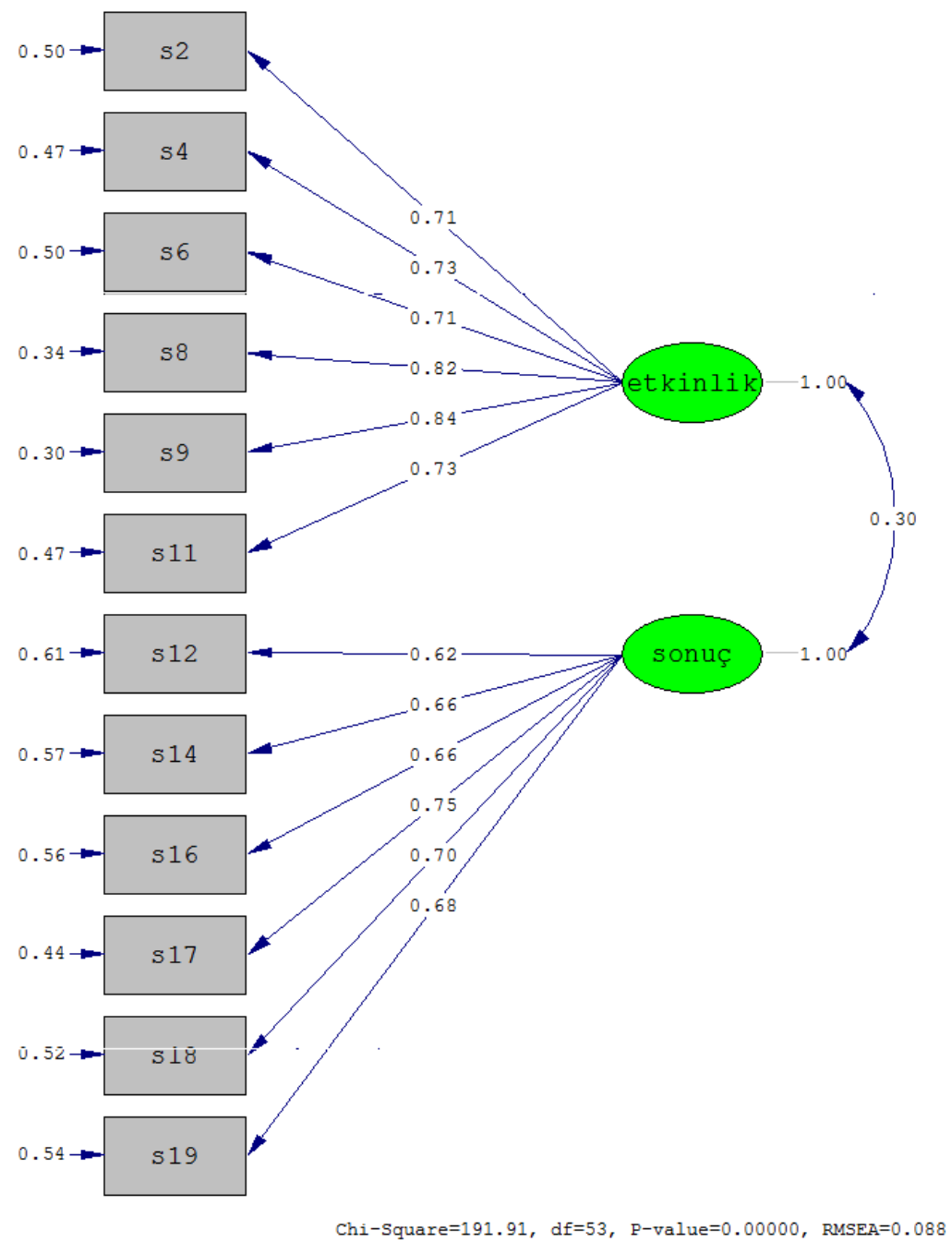

Şekil 1: Path Diyagram1

DFA sonucunda gözlenen değişkenlerin $t$ değerlerinin anlamlılık düzeyi kontrol edilmiştir. Bu analizde elde edilen modele ait $\mathrm{t}$ değerleri Şekil 2'de gösterilmektedir. Modelde $\mathrm{t}$ değerleri ile ilgili kırmızı ok bulunmaması, tüm maddelerin .05 düzeyinde anlamlı olduğunu ifade etmektedir (Seçer, 2015). Şekil 2 incelendiğinde, t değerleri ile ilgili kırmızı ok bulunmadığı görülmektedir. Bu nedenle ölçekteki tüm maddelerin .05 düzeyinde anlamlı olduğu tespit edilmiştir. 


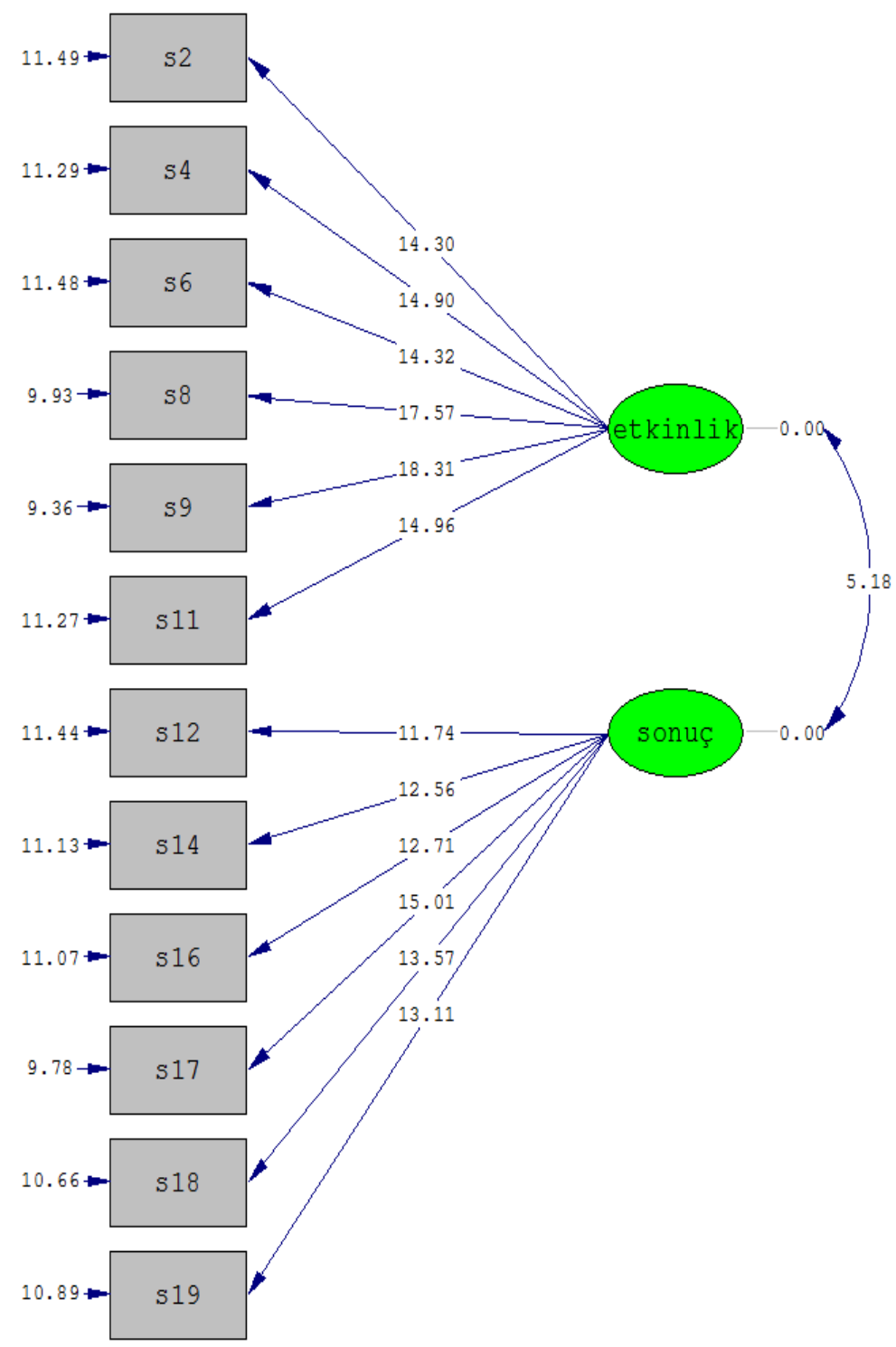

Chi-Square=191.91, df=53, P-value=0.00000, RMSEA $=0.088$

Şekil 2: Gözlenen değişkenlerin $\mathrm{t}$ değerleri diyagramı

\section{Madde Analizi}

FeTeMM ölçeğinin Türkçe formunda yer alan her bir maddenin ölçmek istediği özelliği ölçüp ölçmediğini incelemek amacıyla madde toplam korelasyonları hesaplanmıştır. Ölçeğin \%27 alt ve üst gruplarının madde puanları arasındaki farklara ilişkin t değerlerinin -9,129 ile -12,088 arasında değiştiği ve anlamlı olduğu $(\mathrm{p}<.01)$ tespit edilmiştir (Tablo 8).

Tablo 8: Madde analizi sonuçları

\begin{tabular}{ccccccc}
\hline Madde & Grup & $\mathbf{X}$ & sd & $\begin{array}{c}\text { Madde Top. } \\
\text { Kor. }\end{array}$ & t & p \\
& & & & & \\
\hline s2 & alt\%27 & 3,4245 &, 71645 &, 443 & $-9,964$ &, 000 \\
& ust\%27 & 4,2453 &, 45380 & & $-9,964$ &, 000 \\
\multirow{2}{*}{ s4 } & alt\%27 & 3,4906 &, 78371 &, 518 & $-11,344$ &, 000 \\
& ust\%27 & 4,5377 &, 53762 & & $-11,344$ &, 000 \\
\multirow{2}{*}{ s6 } & alt\%27 & 3,3585 &, 71964 &, 380 & $-9,129$ &, 000 \\
& ust\%27 & 4,1792 &, 58223 & & $-9,129$ &, 000 \\
s8 & alt\%27 & 3,4528 &, 75759 &, 491 & $-10,659$ &, 000
\end{tabular}




\begin{tabular}{ccccccc} 
& ust\%27 & 4,4340 &, 56936 & & $-10,659$ &, 000 \\
s9 & alt\%27 & 3,7642 &, 71116 &, 451 & $-9,158$ &, 000 \\
& ust\%27 & 4,5472 &, 51883 & & $-9,158$ &, 000 \\
s11 & alt\%27 & 3,7453 &, 78147 &, 486 & $-9,284$ &, 000 \\
& ust\%27 & 4,6132 &, 56181 & & $-9,284$ &, 000 \\
s12 & alt\%27 & 2,7736 &, 95900 &, 435 & $-11,100$ &, 000 \\
& ust\%27 & 4,1321 &, 81738 & & $-11,100$ &, 000 \\
s14 & alt\%27 & 3,4811 &, 85335 &, 483 & $-11,091$ &, 000 \\
& ust\%27 & 4,5755 &, 55116 & & $-11,091$ &, 000 \\
s16 & alt\%27 & 2,9434 &, 91371 &, 416 & $-10,567$ &, 000 \\
& ust\%27 & 4,2170 &, 83955 & & $-10,567$ &, 000 \\
s17 & alt\%27 & 3,4057 &, 81391 &, 539 & $-11,233$ &, 000 \\
& ust\%27 & 4,4811 &, 55603 & & $-11,233$ &, 000 \\
s18 & alt\%27 & 2,9245 &, 93297 &, 461 & $-12,088$ &, 000 \\
& ust\%27 & 4,3208 &, 73740 & & $-12,088$ &, 000 \\
\multirow{2}{*}{ s19 } & alt\%27 & 3,0849 &, 88499 &, 445 & $-10,986$ &, 000 \\
& ust\%27 & 4,3019 &, 71939 & & $-10,986$ &, 000 \\
\hline
\end{tabular}

\section{Güvenirlik}

FeTeMM ölçeğinin Türkçe formunun güvenirliğini tespit etmek için iç tutarlılık katsayısı hesaplanmış ve test-tekrar test yöntemi kullanılmıştır. Büyüköztürk (2014)'e göre .70 ile 1.0 arasındaki değerler yüksek, .70 ile .30 arasındaki değer orta ve .30 ile 0.00 arasındaki değerler düşük düzey ilişkiyi göstermektedir. Test-tekrar test yöntemi kapsamında, FeTeMM ölçeğinin iki uygulaması arasında yüksek düzeyde, pozitif ve anlamlı bir ilişki olduğu tespit edilmiştir [r(41)=0.71, $\mathrm{p}<.01]$.

Ölçeğin alt boyutlarının iç tutarlılık katsayıları Tablo 9'da verilmiştir. İç tutarlılık katsayısının .70 ve üzeri olması, ölçme aracının yüksek düzeyde güvenilir olduğunu göstermektedir (Büyüköztürk vd., 2011). Tablo 9 incelendiğinde; Cronbach Alpha katsayılarının 12 maddelik ölçek ve alt boyutları için yüksek düzeyde iç tutarlılığı temsil ettiği tespit edilmiştir.

Tablo 9: Ölçeğin Türkçe formunun psikometrik özellikleri

\begin{tabular}{lll}
\hline Alt Boyutlar & Madde Sayısı & Cronbach Alpha \\
\hline Fen Bilimleri Öğretiminde Özyeterlik İnancı & 6 & .847 \\
Fen Bilimleri Öğretimi Sonucu Beklentileri & 6 & .793 \\
\hline Toplam & 12 & .808 \\
\hline
\end{tabular}

\section{Ölçek Puanlarının Değerlendirilmesi}

Fen Bilimleri öğretmen adayları için uyarlanan FeTeMM Özyeterlik ölçeğinde 12 madde bulunmaktadır. Bu ölçekten alınabilecek en yüksek puan 60 , en düşük puan ise 12 'dir. Ölçekte olumsuz madde bulunmamaktadır. Ölçekten alınan yüksek puanlar, yüksek özyeterlik düzeyini ifade etmektedir. 


\section{Tartışma}

$\mathrm{Bu}$ araştırmanın amac1, Friday Institute for Educational Innovation (2012a) tarafindan geliştirilen Fen Bilimleri Öğretmenlerinin FeTeMM'e Yönelik Özyeterlik ve Tutumları Ölçeği’ni Fen Bilimleri öğretmen adaylarının özyeterlik düzyeyini belirleyecek şekilde Türkçe'ye uyarlamaktır. FeTeMM ölçeğinin Türkçe formunun dilsel eş değerliğinin incelenmesi sonucunda orijinal form ile Türkçe form arasında dilsel eş değerlik bulunmuştur. Ölçeğin yapı geçerliğini incelemek için yapılan AFA hesaplamalarında binişik ve hiçbir faktör altında toplanmayan maddeler çıkarılmıştır. Çalışmanın amacına uygun olarak, orijinal ölçeğin Fen Bilimleri öğretiminde özyeterlik inancı ve Fen Bilimleri öğretimi sonucu beklentileri boyutlarının Fen Bilimleri öğretmen adaylarının özyeterlik düzeyini belirlediği tespit edilmiştir. Bu nedenle orijinal ölçeğin ilk iki faktör yapısının doğruluğunu test etmek için DFA uygulanmıştır. Tespit edilen uyum indeksi değerleri incelendiğinde, 12 maddeden oluşan iki faktörlü yapının model uyumunun doğrulandığı görülmüştür. Ölçekten elde edilen iki faktöre ve ölçeğin tümüne yönelik yapılan iç tutarlılık analizi sonucunda ölçeğin güvenilir olduğu bulunmuştur. Çalışmada hesaplanan \%27 alt ve üst gruplarının madde puanları arasındaki farklara ilişkin t değerleri, ölçeğin madde ayırt edicilik gücünün yeterli düzeyde olduğunu göstermiştir.

Çalışma kapsamında elde edilen veriler, Fen Bilimleri Öğretmen Adaylarının FeTeMM'e Yönelik Özyeterlik Ölçeği'nin (Ek-1, sayfa 107) eğitim alanında kullanılabilecek geçerli ve güvenilir bir ölçek olduğunu göstermektedir. İlgili ölçeğin Fen Bilimleri öğretmen adaylarının FeTeMM'e yönelik özyeterlik düzeyini incelemek isteyen araştırmacılar için etkili ve önemli bir ölçme aracı olacağı düşünülmektedir. Gelecekteki çalışmalarda, ilgili ölçeğin daha geniş örneklem gruplarında geçerlik ve güvenirlik araştırmaları yapılabilir. Buna ek olarak, ölçeğin orijinal formunun tamamını veya diğer boyutlarını Türk kültürüne kazandırma çalışması yapılabilir. 


\section{Extended Summary}

\section{Introduction}

Rapidly changing demands of society require comprehensive innovation in education (Larson \& Miller, 2011). In order to acquire 21 st century skills, individuals, capable of keeping up with the constantly developing society, need ambitious and rigorous education based on Science, Technology, Engineering and Mathematics (STEM) disciplines which was integrated into Science education in 2001 in America (Blair, 2012; Trilling, Fadel \& Partnership for 21st Century Skills, 2009).

STEM education is an interdisciplinary approach enabling students to learn by associating the academic concepts in Science, Technology, and Engineering and Mathematics disciplines with their daily life experiences. This meticulous approach mainly aims at helping students become STEM-literate individuals; in other words, enabling them to use STEM concepts to solve complex and high-level problems (Balka, 2011). Those students know the distinctive features of the STEM domains, understand how these domains shape daily life and raise awareness to solve the difficulties in STEM-related issues (Bybee, 2013).

Removing the traditional boundaries among them; STEM education promote a coherent learning paradigm allowing the students to associate four disciplines, which provides the students with opportunities to encourage themselves, perceive the world holistically and become the leaders of the future (Asunda, 2011). As a result, they have deep knowledge and ability to choose correct and beneficial information among many resources (Krajcik \& Delen, 2017).

STEM education is more effective when the teachers provide a strong and professional learning environment for the students (Fulton and Britton, 2011). It is emphasized that pre-service teacher is the key point for qualifying the teachers for STEM (Rogers, Winship \& Sun, 2015). Therefore, pre-service teachers, as the teachers of the future, should have high self-efficacy and a positive attitude toward STEM approach (Fulton, Doerr and Britton, 2010).

In order to support the education of students to make them keep up with the requirements of 21 st century, pre-service teachers attach importance to have comprehensive and correct information and positive attitude toward STEM (Radloff \& Guzern, 2016); because their self-efficacy is a very reliable predictor of their teaching performance in the future (Thompson \& Kanasa, 2016).

The STEM-related impressions of the pre-service teachers allow us to make a conclusion about how to practice teaching as a profession; which may lead the students to demonstrate a positive view of STEM and orient toward these domains. Therefore, revealing positive impressions of pre-service teachers about STEM may indicate how the future will be shaped.

Based on the nationwide literature reviews, no scales are determined to examine the pre-service science teachers' self-efficacy levels on STEM. However, it has been given more importance to STEM in the field of Science education in recent years, and the necessity has arisen to examine self-efficacy levels of pre-service Science teachers before those teachers start their professional life. In accordance with this great necessity it is aimed at this research to adapt Teacher Efficacy and Attitudes toward STEM Survey- Science Teachers scale developed by the Friday Institute for Educational Innovation (2012a) to Turkish in order to determine the self-efficacy level of pre-service science teachers.

\section{Method}

The population of this research consists of 392 3rd and 4th grade pre-service science teachers studying at the science education programs of Mathematics and Science Education Departments. In the adaptation study of STEMScale to Turkish, these steps were followed; (1) preparation for adaptation study, (2) translation of scale from original language into Turkish, (3) translation of the scale from Turkish into original language, (4) examination of consistency between translations by the expert group, (5) examination of linguistic equivalence, (6) in the sequel of pilot implementation, performing follow-up phases of statistical analysis.

To investigate the linguistic equivalence of the scales, the original and Turkish forms were applied to 46 preservice teachers educated at the third grade of English Language Education Department of Istanbul University, Faculty of Education. At this stage, as Sugar and Gençdoğan (2014) proposed, the original and Turkish forms were 
applied successively. Pearson product-moment correlation coefficients and related-group-t-test were calculated based on the items from two forms.

Construct validity was examined to determine the validity of the Turkish forms of the scales while exploratory factor analysis (EFA) and confirmatory factor analysis (CFA) were applied to examine the construct validity of the original scale. In order to evaluate the reliability of scale, the internal consistency coefficient was calculated and the test-retest method was used. Within the scope of test-retest reliability study; after a three-week interval, Turkish form of scale was applied to 41 pre-service teachers studying at Science Education Department of Faculty of Education in Istanbul University. Following the application, the stability between the scores of the pre-service teachers attending both applications was calculated. Item-total correlation and comparison of $27 \%$ upper and lower groups were calculated for examining item discrimination of the scale.

\section{Results}

The data obtained from the Turkish form of the STEM scale indicated a normal distribution $(\mathrm{p}=.052>.050)$. It was concluded that the original form of the STEM-scale was linguistically equivalent to the Turkish form of it ( $\mathrm{r}=.98$, $\mathrm{p}<.01)$. Therefore, it could be said that the linguistic equivalence of the scales were achieved.

In order to investigate whether the data were appropriate for factor analysis, Kaiser-Meyer-Olkin (KMO) index was calculated and the Bartlett's Test of Sphericity was administered. KMO index was calculated as .897 and the Bartlett's Test of Sphericity was evaluated to be significant $\left(X^{2}=12,538.273 ; \mathrm{p}=.00\right)$. These results showed that the Turkish form of STEM scale was suitable for factor analysis.

For determination of validity, EFA and CFA were used. EFA was applied to examine the presence of Turkish form in the original 7-factors scale. Regarding to this examination, overlapping items and items which are not combined under any factors are extracted. According to this examination; it was understood that Science Teaching Efficacy factor and Beliefs and Science Teaching Outcome Expectancy factor, the first two factors of the original scale, could determine the self-efficacy levels of pre-service Science teachers. Accordingly; CFA was performed to verify the first two factors of the original scale thanks to the gathered data. It has been determined that the results of the fit index were within acceptable limits (NFI=.896, NNFI=.903, IFI=.923, RFI=.871, CFI=.922, GFI=.910, $\mathrm{AGFI}=.868, \mathrm{RMR}=.0732, \mathrm{RMSEA}=.0881, \mathrm{X}^{2} / \mathrm{sd}=3.6209$ ). According to the path diagram maintained as a result of CFA, the factor loadings of the items were changed between .62 and .84 . In addition to that, all the items in the scale were found to be significant at .05 level.

Item-total correlations were calculated to examine whether each item measured the intended aspects or not. It was determined that the t-values for differences between the total item scores of the $27 \%$ upper and lower groups were between -9.129 and -12.088 and significant $(\mathrm{p}<.01)$.

To evaluate the reliability of the scale, the internal consistency coefficient was calculated and the test-retest method was used. Owing to the test-retest method, a high positive correlation was detected between the two STEM scale applications $[\mathrm{r}(41)=0.71, \mathrm{p}<.01]$. Cronbach's alpha coefficient of whole scale was calculated as .808; which represents a high level of internal consistency for the whole 12-items scale and two sub-dimensions.

\section{Discussion}

The results of this study shows that the Pre-Service Science Teachers' Self-Efficacy toward Science, Technology, Engineering, and Mathematics (STEM) Survey (Appendix-1) is a valid and reliable scale that can be used in the field of education. It is believed that this scale is an effective and important instrument for researchers planning to investigate the self-efficacy level of pre-service Science teachers for STEM. For future studies, validity and reliability studies of this scale can be carried out in larger sample groups. In addition to that, it is possible to adapt the whole of the original form or other sub-dimensions of the scale into Turkish culture. 


\section{Kaynakça / References}

Adams, W., \& Sheslow, W. (2003). Wide range assessment of memory and learning (2nd ed.). Wilmington, DE: Wide Range.

Akoğlu, G. (2011). Gelişimsel dil bozukluğu olan ve normal gelişim gösteren çocuklarda sözdizimini anlama becerileri ile sözel çalışma belleği ilişkisinin incelenmesi (Yayınlanmış Yüksek lisans tezi). Ankara Üniversitesi, Ankara.

Akoğlu, G. \& Acarlar, F. (2014). Gelişimsel dil bozukluklarında söz dizimi anlama ve sözel çalışma belleği ilişkisinin incelenmesi. Türk Psikoloji Dergisi, 29 (73), 89-103.

Alloway, T. P., \& Alloway R. (2010). Investigating the predictive roles of working memory and IQ in academic attainment. Journal of Experimental Child Psychology, 106, 20-29.

Alloway, T. P., \& Archibald, L. M. D. (2008). Working memory and learning in children with developmental coordination disorder and specific language impairment. Journal of Learning Disabilities, 3, 251- 262.

Alloway, T. P., Gathercole, S. E., Kirkwood, H., \& Elliott, J. (2008). Evaluating the validity of the automated working memory assessment. Educational Psychology, 28(7), 725-734.

Alloway, T. P., Gathercole, S. E., \& Pickering, S. J. (2006). Verbal and visuospatial short-term and working memory in children: Are they separable? Child development, 77(6), 1698-1716.

Alloway, T. P., Gathercole, S. E., Willis, C., \& Adams, A. M. (2004). A structural analysis of working memory and related cognitive skills in young children. Journal of experimental child psychology, 87(2), 85-106.

Alp, E., \& Özdemir, B. (2007). Çocuklarda akıcı zekanın (gf) bilgi işleme hızı, kısa süreli bellek ve çalışma belleği kapasitesi ile ilişkisi. Türk Psikoloji Dergisi, 22(60), 1-15.

Altun, A., \& Çevik, V. (2012). Çoklu ortam tabanlı bir görev ile çalışma belleğinin ölçülmesi. Hacettepe Üniversitesi Ĕ̈itim Fakültesi Dergisi, Özel Sayı 1, 32-40.

Archibald, L. M., \& Gathercole, S. E. (2006). Visuospatial immediate memory in specific language impairment. Journal of Speech, Language, and Hearing Research, 49(2), 265-277.

Babayiğit, S., \& Stainthorp, R. (2009). Component processes of early reading, spelling, and narrative writing skills in Turkish: A longitudinal study. Reading and Writing, 23, 539- 568.

Babayiğit, S., \& Stainthorp, R. (2011). Modeling the relationships between cognitive-linguistic skills and literacy skills: New insights from a transparent orthography. Journal of Educational Psychology, 1, 169- 189.

Baddeley, A., \& Wilson, B. A. (1994). When implicit learning fails: Amnesia and the problem of error elimination. Neuropsychologia, 32(1), 53-68.

Baddeley, A. (1996). Exploring the central executive. The Quarterly Journal of Experimental Psychology: Section A, 49(1), 5-28.

Baddaley, A. (2000). The episodic buffer: a new component of working memory. Trends in Cognitive Sciences, 11, 417- 422.

Baddaley, A. (2006). Working memory: An overview. S. Pickering (Ed.). Working memory and education (pp. 1-31). Academic Press.

Baddeley, A. (2007). Oxford psychology series: Vol. 45. Working memory, thought, and action. New York, NY, US: Oxford University Press. 
Baddeley, A., Gathercole, S., ve Papagno, C. (1998). The phonological loop as a language learning device. Psychological review, 105(1), 158.

Baddeley, A. D., \& Hitch, G. (1974). Working memory. Psychology of learning and motivation, 8, 47-89.

Baddaley, A., \& Hitch, G. J. (1994). Developments in the concept of working memory. Neuropsychology, 4, 485-493.

Baddaley, A., \& Logie, R. H. (1999). Working memory: The multiple component model. In A. Miyake ve P. Shah (Eds.). Models of Working Memory: Mechanisms of Active Maintenance And Executive Control (pp. 28- 61). New York, NY, US: Cambridge University Press.

Berninger, V. W., \& Richards, T. L. (2002). Brain literacy for educators and psychologists. San Diego, CA, US: Academic Press.

Bull, R., \& Scerif, G. (2001). Executive functioning as a predictor of children's mathematics ability: Inhibition, switching, and working memory. Developmental Neuropsychology, 19(3), 273-293.

Ciappe, P., Hasher, L., \& Siegel, L. (2000). Working memory, inhibitory control and reading disability. Memory and Cognition, 28(1), 8-17.

Clair-Thompson, L. H., \& Gathercole, S. E. (2006). Executive functions and achievements in school: Shifting, updating, inhibition, and working memory. The Quarterly Journal of Experimental Psychology, 59(4), 745759.

Cohen, M. (1997). Children's memory scale (CMS). San Antonio, TX: The Psychological Corporation.

Crain, S., Shankweiler, D., Macaruso, P., \& Bar-Shalom, E. (1990). Working memory and comprehension of spoken sentences: Investigations of children with reading disorder. In G. Vallar \& T. ShaIlice (Eds.), Neuropsychological impairments of short-term memory (pp. 477-508). Cambridge, UK.: Cambridge University Press.

Çokluk, Ö., Şekercioğlu, G. \& Büyüköztürk, Ş. (2016). Sosyal bilimler için çok değişkenli istatistik: SPSS ve LISREL uygulamaları. Ankara: Pegem Akademi.

Dehn, M. (2008). Working memory and academic learning: Assessment and intervention. New Jersey. John Wiley and Sons, İnc., Hoboken.

Dehn, M. (2010). Long- term memory problems in children and adolescens: Assessment, intervention and effective instruction. New Jersey. John Wiley and Sons, Inc., Hoboken.

De Weerdt, F., Desoete, A., \& Roeyers, H. (2013). Working memory in children with reading disabilities and/or mathematical disabilities. Journal of learning disabilities, 46(5), 461-472.

Doğan, M. (2011). İşitme kayıpl çocukların ve normal işiten çocukların çalışma belleği ve kısa süreli bellek yönünden incelenmesi (Doktora tezi). Anadolu Üniversitesi, Eskişehir.

Engle, R. W. (1996). Working memory and retrieval: An inhibition-resource approach. In J. T. E. Richardson, R. W. Engle, L. Hasher, R. H. Logie, E. R. Stoltzfus, \& R. T. Zacks (Eds.), Working memory and human cognition (pp. 89-119). New York: Oxford University Press.

Engle, R. W. (2002). Working memory capacity as executive attention. Current directions in psychological science, 11(1), 19-23.

Gathercole, S. E. (1999). Cognitive approaches to the development of short-term memory. Trends in cognitive sciences, 3(11), 410-419. 
Gathercole, S. E., Alloway, T. P., Willis, C., \& Adams, A. (2006). Working memory in children with reading disabilities. Journal of experimental child Psychology, 93(3), 265-281.

Gathercole, S. E., Brown, L., \& Pickering, S. J. (2003). Working memory assessments at school entry as longitudinal predictors of National Curriculum attainment levels. Educational and Child Psychology, 20(3), 109-122.

Gathercole, S. E., \& Pickering, S. (2000). Working memory deficits in children with low achievements in the national curriculum at 7 years of age. British Journal of Educational Psychology, 70, 177-194.

Gathercole, S. E., Pickering, S., Knight, C., \& Stegmann, Z. (2004). Working memory skills and educational attainment: Evidence from national curriculum assessments at 7 and 14 years of age. Applied Cognitive Psychology, 18,1-16.

Geary, D. C., Hoard, M. K., Byrd-Craven, J., Nugent, L., \& Numtee, C. (2007). Cognitive mechanisms underlying achievement deficits in children with mathematical learning disability. Child development, 78(4), 1343-1359.

Harrison, T. L., Shipstead, Z., \& Engle, R. W. (2015). Why is working memory capacity related to matrix reasoning tasks?. Memory ve cognition, 43(3), 389-396.

Holmes, J., \& Adams, J. (2006). Working memory and children's mathematical skills: Implications for mathematical development and mathematics curricula. Educational Psychology, 3, 339-366.

Hu, Y., Hitch, G. J., Baddaley, A.D., Zhang, M., \& Allen, R. J. (2014) Executive and perceptual attention play different roles in visual working memory: Evidence from suffix and strategy effects. Journal of Experimental Psychology, 4, 1665-1678.

Jerman, O., Reynolds, C., \& Swanson, H. L. (2012). Does growth in working memory span or executive processes predict growth in reading and math in children with reading disabilities? Learning Disability Quarterly, 35(3), 144-157.

Kafadar, H. (2004). Akıcı zekanın performans zeka, sözel zeka, yönetici işlevler, çalışma belleği, seçici dikkat ve kısa süreli bellek süreçlerinden yordanması (Doktora tezi). Hacettepe Üniversitesi, Ankara.

Karaca, A., Yıldırım, N., Ankaralı, H., Açıkgöz, F., \& Akkuş, D. (2015). Hemşirelik öğrencileri için algılanan stres, biyo-psiko-sosyal cevap ve stresle başetme davranışları ölçeklerinin Türkçe’ye uyarlanması. Journal of Psychiatric Nursing, 6(1), 15-25.

Karakelle, S., \& Ertuğrul, Z. (2012). Zihin kuramı ile çalışma belleği, dil becerisi ve yönetici işlevler arasındaki bağlantılar küçük (36-48ay) ve büyük (53-72 ay) çocuklarda farklılık gösterebilir mi? Türk Psikoloji Dergisi, $2(70), 1-21$.

Kesikçi, H., \& Amado, S. (2005). Okuma güçlügü olan çocukların fonolojik bellek, kısa süreli bellek ve WISC-R ölçeği puanlarına ait bir inceleme. Türk Psikoloji Dergisi, 20 (55), 99-110.

Kroesbergen, E. H., Van't Noordende, J. E., \& Kolkman, M. E. (2012). Training working memory in kindergarten children: Effects on working memory and early numeracy. Child Neuropsychology, 1, 23-37.

Mammarella, I. C., Lucangeli, D., \& Cornoldi, C. (2010). Spatial working memory and arithmetic deficits in children with nonverbal learning difficulties. Journal of Learning Disabilities, 43(5), 455-468.

Marton, K., \& Eichorn, N. (2014). Interaction between working memory and long-term memory: A study in children with and without language impairment. Zeitschrift Für Pyschologie, 2, 90- 99.

Nyman, A., Taskinen, T., Grönroos, M., Haataja, L., Lähdetie, J., \& Korhonen, T. (2010). Elements of working memory as predictors of goal-setting skills in children with attention-deficit/hyperactivity disorder. Journal of Learning Disabilities, 43(6), 553-562. 
Özgür Yılmaz, Ç. (2016). 5-10 yaş grubu çocuklara yönelik çalışma belleği ölçeğinin geçerlik-güvenirlik çalışması (Yayınlanmamış Yüksek Lisans Tezi). Ankara Üniversitesi, Ankara.

Peng, P., \& Fuchs, D. (2017). A Randomized control trial of working memory training with and without strategy instruction: Effects on young children's working memory and comprehension. Journal of Learning Disabilities, 50(1), 62-80.

Passolunghi, M. C., \& Siegel, L. S. (2004). Working memory and access to numerical information in children with disability in mathematics. Journal of Experimental Child Psychology, 88, 348-367.

Pickering, S. J., Gathercole, S. E., Hall, M., \& Lloyd, S. A. (2001). Development of memory for pattern and path: Further evidence for the fractionation of visuo-spatial memory. The Quarterly Journal of Experimental Psychology: Section A, 54(2), 397-420.

Pimperton, H., \& Nation, K. (2014). Poor comprehenders in the classroom: teacher ratings of behavior in children with poor reading comprehension and its relationship with individual differences in working memory. Journal of Learning Disabilities, 47(3), 199-207.

Rajendran, G., Alloway, T. P., \& Archibald, L. (2009). Working memory in children with developmental disorders. Journal of Learning Disabilities, 42(4), 372-382.

Reynolds, C. R., \& Voress, J. K. (2007). Ölçek of Memory and Learning (2nd ed.). Austin: TX: PRO-ED.

Ricker, T. J., \& Cowan, N. (2014). Differences between presentation methods in working memory procedures: A matter of working memory consolidation. Journal of Experimental Psychology: Learning, Memory, and Cognition, 40(2), 417.

Sayar, F., \& Turan, F. (2012). Okuma gelişiminde üst dil farkındalığı, ses bilgisel süreçler ve bellek süreçlerinin etkisi: Kısa süreli bellek ve çalışma belleği. Ankara Üniversitesi Eğitim Bilimleri Fakültesi Özel Eğitim Dergisi, 13 (2), 49-64.

Schweppe, J., \& Rummer, R. (2014). Attention, working memory, and long-term memory in multimedia learning: an integrated perspective based on process models of working memory. Educational Psychology Review, 26(2), 285-306.

Service, E. (1992). Phonology, Working Memory, and Foreignlanguage Learning. The Quarterly Journal of Experimental Psychology, 45a (1) 21-50.

Swanson, H. L. (1995). Effects of dynamic ölçeğing on the classification of learning disabilities: The predictive and discriminant validity of the Swanson-Cognitive Processing Ölçek (S-CPT). Journal of Psychoeducational Assessment, 13(3), 204-229.

Swanson, H. L. (2000). Are working memory deficits in readers with learning disabilities hard to change. Journal of Learning Disabilities, 6, 551- 566.

Swanson, H. L. (2001). Research on interventions for adolescents with learning disabilities: A meta-analysis of outcomes related to higher-order processing. The Elementary School Journal, 101(3), 331-348.

Swanson, H. L. (2006). Working memory and dynamic scale for children with learning disabilities. In S. Pickering (Ed.). Working memory and education (p. 125-156). New York, NY: Academic Press.

Swanson, H. L. (2011). Dynamic ölçeğing, working memory, and reading comprehension growth in children with reading disabilities. Journal of Learning Disabilities, 44(4), 358-371.

Swanson, H. L., Kehler, P., \& Jerman, O. (2010). Working memory, strategy knowledge, and strategy instruction in children with reading disabilities. Journal of Learning Disabilities, 43(1), $24-47$. 
Swanson, H. L., \& Sachse-Lee, C. (2001). Mathematical problem solving and working memory in children with learning disabilities: Both executive and phonological processes are important. Journal of experimental child psychology, 79(3), 294-321.

Tercan, E., Ergin, H., \& Amado, S. (2012). Okuma güçlüğü yaşayan çocuklarda çalışma belleğinin fonolojik depo açısından incelenmesi. Türk Psikoloji Dergisi, 27(69), 65-75.

Torn, A., \& Page, M. (2009). Interactions between short-term and long-term memory in the verbal domain. New York. Psychology Press.

Turgut, M. F., \& Baykul, Y. (2010). Eğitimde ölçme ve değerlendirme. Ankara: Pegem Akademi.

Urbina, S. (2004). Essentials of pyschological ölçeğing. New Jersey: John Wiley ve Sons, Inc., Hoboken.

Wechsler, D. (1997). WMS-III: Wechsler memory scale administration and scoring manual. Psychological Corporation.

Yalın, A., \& Karakaş, S. (1994). Görsel işitsel sayı dizisi ölçeği a formunun bir türk çocuk örnekleminde güvenirlik, geçerlik ve standardizasyon çalışması. Türk Psikoloji Dergisi, 9(32), 6-14.

Ek-1: Fen Bilimleri Öğretmen Adaylarının Fen-Teknoloji-Mühendislik-Matematik (FeTeMM)'e Yönelik Özyeterlik Ölçeği

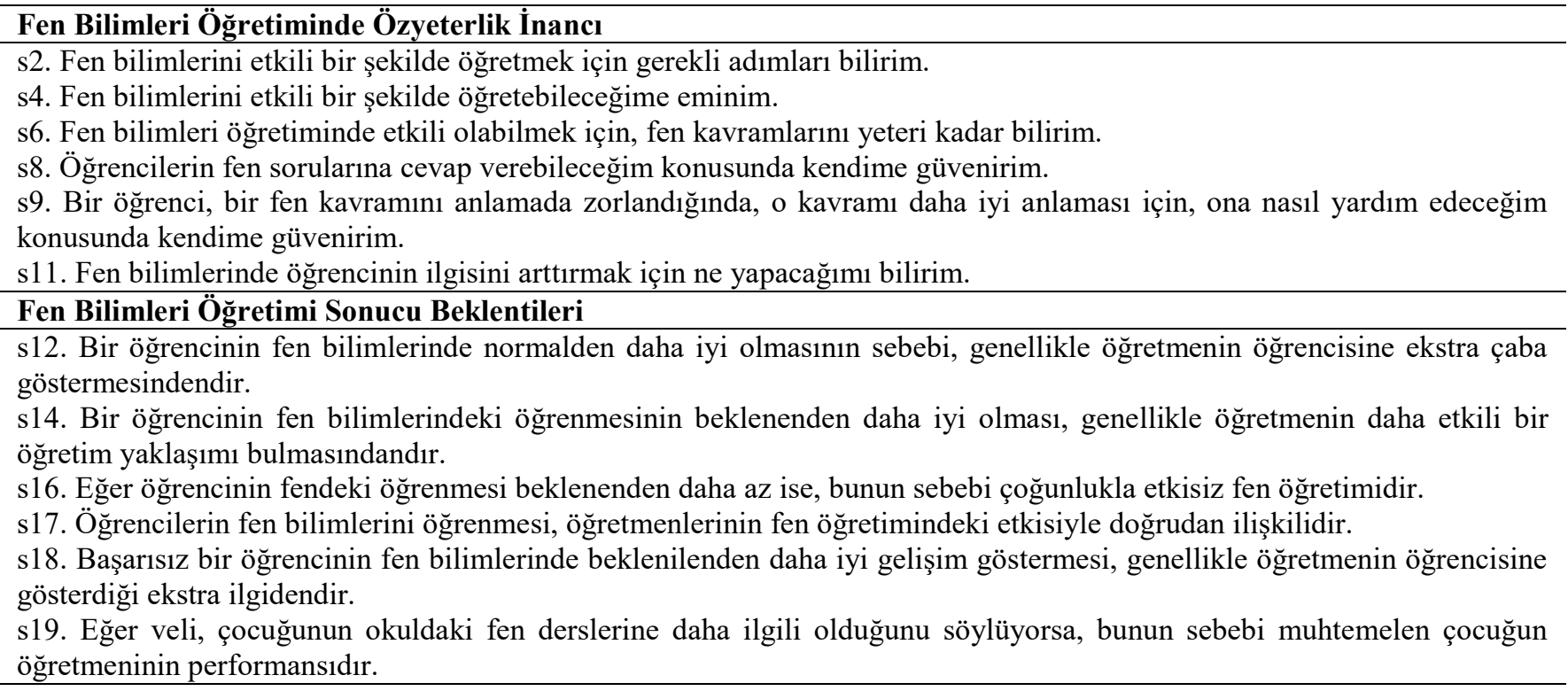

